Japanese Journal of Physiology, 31, 957-961, 1981

\title{
Diminished Circadian Rhythm of Locomotor Activity after Vagotomy in Rats
}

\author{
Shinji Itoh, Goro Katsuura, and Ryoji Hirota \\ Shionogi Research Laboratories, Fukushima-ku, Osaka, 553 Japan
}

\begin{abstract}
Summary Circadian rhythm of spontaneous locomotor activity, which is normally highly elevated during the dark phase of a day, diminished after ablation of the vagal nerves in rats with intact suprachiasmatic nuclei under light-dark cyclic conditions. This suggests that gastrointestinal activity affects the circadian rhythm of locomotor activity through the afferent pathway of the vagus.
\end{abstract}

Recently, an increasing amount of literature has appeared on the role of the suprachiasmatic nuclei (SCN) in regulating circadian rhythm of locomotor activity (STEPhan and Zucker, 1972; Stetson and WAtson-Whitmyre, 1976). Similar effects of SCN ablation on the plasma corticosterone, food and water intake, sleepwakefulness cycle, body temperature and pineal enzyme activities have been reported by a number of investigators. However, KRIEGER et al. (1977) and MOORE (1980) demonstrated that destruction of SCN did not alter the circadian rhythms induced by food and/or water deprivation schedule. We found that circadian rhythm of plasma corticosterone was at least in part affected by gastrointestinal activity through the vagus (Iтон et al., 1981). In the present study we observed a diminished rhythm in the spontaneous locomotor activity after ablation of the vagal nerves in rats.

Female Wistar rats, 10 weeks of age, were used, since female rats are more active during the night than males, and changes in locomotor activity caused by experimental procedures are expected to be easily demonstrable as reported by SchNeIDER and Norton (1979). The animals were housed 3 in a cage at a constant temperature of $25 \pm 2^{\circ} \mathrm{C}$ with a 12-hr light and 12-hr dark cycle, the light period starting at 07:00 hr. Free access to rat biscuits (Oriental Yeast Co.) and drinking water was allowed. Subdiaphragmatic vagotomy was carried out under Nembutal anesthesia. Through an upper abdominal midline incision the esophagus was isolated from its surrounding tissue near the esophago-gastric junction and then the vagal nerve trunks, including the hepatic branch, were removed. In sham-operated rats the isolated vagal nerves were kept intact. Penicillin powder

Received for publication April 4, 1981

伊藤真次, 勝浦五郎, 広田良二 
was applied in order to prevent infections. The operated animals were kept singly and allowed 2 weeks for recovery. The stomachs of the vagotomized rats showed atonic distension, and vagotomy was verified anatomically using a dissecting microscope.

Locomotor activity was monitored by the use of an Automex (Columbus Instruments) which displays elevated magnetic field counts corresponding to greater activity of a single rat in a cage. After allowing the rats to become accustomed to a new environment in the apparatus for $6 \mathrm{hr}$, the activity was recorded as counts per hr from 15:00 over a period of $24 \mathrm{hr}$. For statistical analysis Student's $t$-test was used.

Spontaneous locomotor activity during the day and night was expressed as average counts per hr per rat, and the results summarized in Table 1. The average body weight of the vagotomized rats was approximately $10 \%$ less than the values of control groups, and the total day activity was almost half of the control ones. Dark/light period ratios of the activity (D/L) were, as indicated in Fig. 1, 2.29 0.152 (S.E.M.) in the intact rats and $2.25 \pm 0.275$ in the sham-operated ones, while the ratio of vagotomized rats was only $1.37 \pm 0.16$ and in these rats average counts per hr during the dark phase were $44 \%$ of the values in control groups. Moreover, the difference during the dark and light period in average counts per hr was not significant in the vagotomized group.

The present results indicated that the circadian rhythm of spontaneous locomotor activity diminished after ablation of the vagal nerves. Vagotomy is known to delay the time of gastric emptying and in turn decreases the food intake. This is true since highly significant body weight loss was observed in the vagotomized rats. In this regard, KoBAYASHI and TAKAHASHI (1979) reported that circadian rhythms of adrenocortical activity and total locomotor activity progressively faded out in rats subjected to a prolonged food deprivation 7-8 days. Consequently, the diminished rhythm in the vagotomized rats might result, at

Table 1. Spontaneous locomotor activity during dark and light period in normal, sham-operated, and vagotomized rats 2 weeks after surgery.

\begin{tabular}{|c|c|c|c|c|c|c|}
\hline \multirow{2}{*}{ Group } & \multirow{2}{*}{$\begin{array}{c}\text { Age } \\
\text { (weeks) }\end{array}$} & \multirow{2}{*}{$\begin{array}{l}\text { No. of } \\
\text { rats }\end{array}$} & \multirow{2}{*}{$\begin{array}{l}\text { Body } \\
\text { weight } \\
\text { (g) }\end{array}$} & \multicolumn{2}{|c|}{$\begin{array}{l}\text { Locomotor activity } \\
\text { (counts } /(\text { hr } \cdot \text { rat }))\end{array}$} & \multirow{2}{*}{$t$-Test } \\
\hline & & & & Dark period & Light period & \\
\hline Normal & 12 & 10 & $202 \pm 2.2$ & $637 \pm 34$ & $285 \pm 16$ & $P<0.001$ \\
\hline $\begin{array}{l}\text { Sham-operated } \\
t \text {-Test }\end{array}$ & 12 & 10 & $206 \pm 3.3$ & $629 \pm 38$ & $269 \pm 11$ & $P<0.001$ \\
\hline vs. normal & & & N.S. & N.S. & N.S. & \\
\hline $\begin{array}{l}\text { Vagotomized } \\
t \text {-Test }\end{array}$ & 12 & 10 & $183 \pm 3.0$ & $279 \pm 39$ & $210 \pm 25$ & N.S. \\
\hline vs. normal & & & $P<0.001$ & $P<0.001$ & $P<0.05$ & \\
\hline vs. sham-operated & & & $P<0.001$ & $P<0.001$ & $P<0.05$ & \\
\hline
\end{tabular}

Mean \pm S.E.M., N.S. $=$ not significant. 


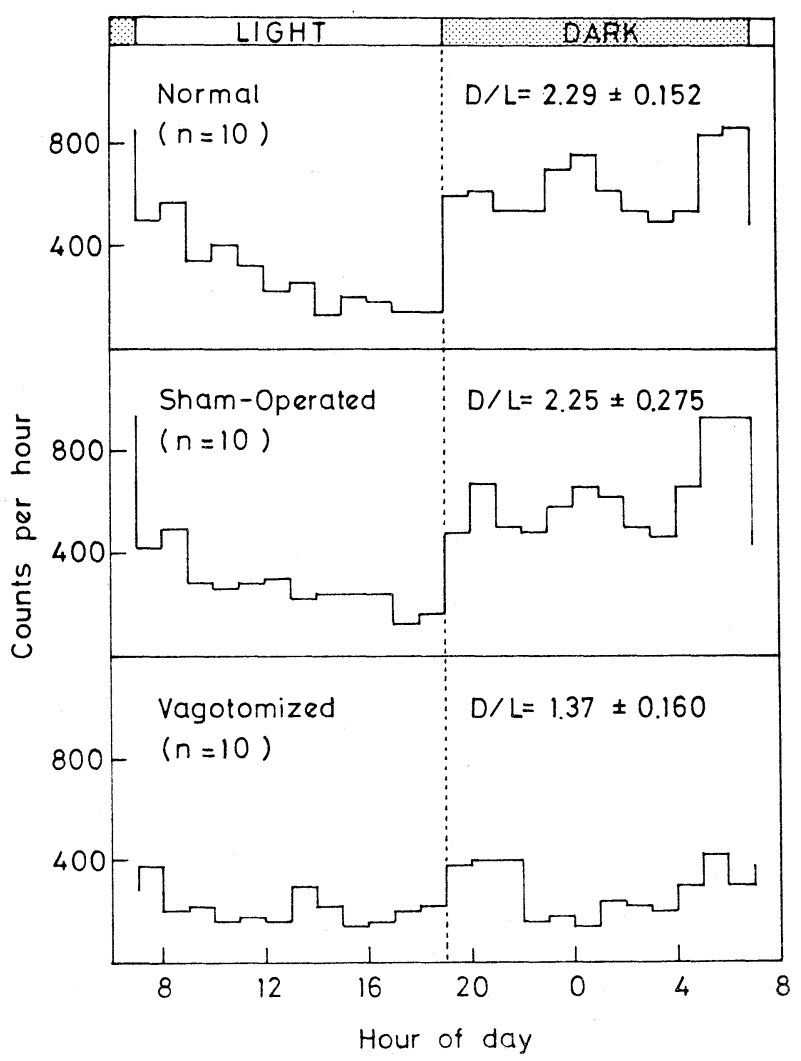

Fig. 1. Circadian rhythm of spontaneous locomotor activity in normal, sham-operated, and vagotomized rats. Average $1-\mathrm{hr}$ counts are indicated. $\mathrm{D} / \mathrm{L}$ ratios were calculated from the average counts per hr during the dark and light phase, respectively.

least in part, from the reduced gastrointestinal activity without any substantial alteration of the circadian rhythm generating system.

However, diminished rhythm in the vagotomized rats may suggest that the lack of visceral input through the vagus reduced the rhythm pattern. In this connection, LOUIS-SYLVESTRE (1978) found that the circadian rhythms of both metabolic and feeding patterns were abolished in vagotomized rats, in which all subdiaphragmatic afferent and efferent vagal fibers were interrupted. Moreover, KRALY (1978) and KrALY et al. $(1975,1978)$ reported that subdiaphragmatically vagotomized rats showed disordered food-related drinking and drank less after cellular dehydration induced by intraperitoneal hypertonic saline. Drinking response to $\beta$-adrenergic activation by isoprenaline was also abolished. These findings were confirmed by ANIKA et al. (1979). CLASSEN et al. (1979) also demonstrated that vagotomized rats drank less than controls during the night, but more during the day. According to Rowland (1980), vagotomized rats showed 
much reduced drinking compared with controls during intravenous infusion of angiotension II. However, their drinking response to intracerebroventricularly administered angiotensin II was less affected. Thus, the possible role of the vagus nerve in the mediation of angiotensin and other types of drinking was suggested. From these observations, it is apparent that the circadian rhythms of food intake and drinking are disordered by abdominal vagotomy. The decreased spontaneous locomotor activity after subdiaphragmatic vagotomy might be related not only to reduced food intake but also disordered water intake.

Although SCN have definitely been shown as an important component of circadian rhythm entraining mechanisms in the central nervous system, alteration of feeding and/or drinking has demonstrated to be a potent stimulus affecting the rhythm pattern (ITOH et al., 1980; KRIEGER et al., 1977; MOORE, 1980). In this regard, the occurrence of sensory-visceral projection to the cerebral cortex (Newman, 1962) and to the cerebellar cortex (HENNEMANn and Rubia, 1978; RUBIA, 1970) have been reported and, more recently, JEANningros and MeI (1980) indicated that the vagal and splanchnic inputs reach the ventromedial nucleus and other parts of the hypothalamus. In line with these reports, our present observation suggests that the gastrointestinal activity may affect the circadian rhythm regulating system and that the afferent pathway through the vagal nerve may be involved in this system. Interruption of signals from the hepatic-portal system could not be excluded and, therefore, further experiments should be carried out in order to clarify the underlying mechanisms by which ablation of the vagal nerves diminished normal rhythmicity in the presence of intact SCN under a light-dark cyclic condition, together with the long-term effect of vagotomy.

\section{REFERENCES}

AnIKa, S. M., Houpt, T. R., and Houpt, T. A. (1979) Recovery from disordered drinking by vagotomized rats. Physiol. Behav., 22: 605-607.

Classen, W., Martin, J. R., and Battig, K. (1979) Computer-compatible system for continuous volumetric measurement of water consumption. Experientia, 35: 1270-1272.

Hennemann, H. E. and Rubia, J. F. (1978) Vagal representation in the cerebellum of the cat. Pflügers Arch. Ges. Physiol., 375: 119-123.

Iтон, S., Katsuura, G., and Hirota, R. (1980) Conditioned circadian rhythm of plasma corticosterone induced by food restriction in the rat. Jpn. J. Physiol., 30: 365-375.

Iтон, S., Katsuura, G., Hirota, R., and Botan, Y. (1981) Circadian rhythm of plasma corticosterone in vagotomized rats. Experientia, 37: 380-381.

JeAnningros, R. and Mei, N. (1980) Vagal and splanchnic effects at the level of the ventromedian nucleus of the hypothalamus (VMH) in the cat. Brain Res., 185: 239-251.

KobAYASHI, K. and TAKAHASHI, K. (1979) Prolonged food deprivation abolishes the circadian adrenocortical rhythm, but not the endogenous rhythm in rats. Neuroendocrinology, 29: 207-214.

Kraly, F. S. (1978) Abdominal vagotomy inhibits osmotically induced drinking in the rat. J. Comp. Physiol. Psychol., 92: 999-1013.

Kraly, F. S., GibBs, J., and SmITH, G. P. (1975) Disordered drinking after abdominal vagotomy. 
Nature, 258: 226-228.

Kraly, F. S., Smith, G. P., and Carty, W. J. (1978) Abdominal vagotomy disrupts foodrelated drinking in the rat. J. Comp. Physiol. Psychol., 92: 196-203.

Krieger, D. T., Hauser, H., and Krey, L. C. (1977) Suprachiasmatic nuclear lesions do not abolish food-shifted circadian adrenal and temperature rhythmicity. Science, 197: 398-399.

LOUIS-SYLVESTRE, J. (1978) Feeding and metabolic patterns in rats with truncular vagotomy or with transplanted $\beta$-cells. Am. J. Physiol., 235: E119-E125.

Moore, R. Y. (1980) Suprachiasmatic nucleus: Secondary synchronizing stimuli and the central neural control of circadian rhythms. Brain Res., 183: 13-28.

Newman, P. P. (1962) Single unit activity in the viscero-sensory areas of the cerebral cortex. J. Physiol. (Lond.), 160: 284-297.

Rowland, N. (1980) Impaired drinking to angiotensin II after subdiaphragmatic vagotomy in rats. Physiol. Behav., 24: 1177-1180.

RubiA, F. J. (1970) The projection of visceral afferents to the cerebellar cortex of the cat. Pflügers Arch. Ges. Physiol., 320: 97-110.

SCHNEIDER, B. F. and Norton, S. (1979) Circadian and sex differences in hyperactivity produced by amphetamine in rats. Physiol. Behav., 22: 47-51.

STEPHAN, F. K. and ZuCKER, I. (1972) Circadian rhythms in drinking behavior and locomotor activity of rats are eliminated by hypothalamic lesions. Proc. Natl. Acad. Sci. U.S.A., 69: 1583-1586.

Stetson, M. H. and Watson-Whitmyre, M. (1976) Nucleus suprachiasmatics: The biological clock in the hamster? Science, 191: 197-199. 